\title{
PRIHVATANJE RAZLIKA: FEMINISTIČKA KRITIKA U SRBIJI U POSTSOCIJALISTIČKOM PERIODU ${ }^{1}$
}

Tekst ima za cilj da predstavi istoriju jednog istraživačkog interdisciplinarnog polja koje je bilo polje razlike u odnosu na samu nauku o književnosti, ali i na feminističku teoriju. Tekst počinje od podatka da su se u socijalističkoj Jugoslaviji zapadne feminističke ideje prvi put čule krajem 70-ih godina na skupu Drug-ca žena, ali da se burna feminističko-teorijska aktivnost odvijala tek od devedesetih godina. Osnivanje Centra za ženske studije, predavanja iz književnosti u Centru, članci i knjige objavljene u tom periodu, svedoče o snažnom razvoju feminističke kritike izvan akademskog sektora. Drugi deo teksta odnosi se na ulazak teorija roda i razlike u akademsku sferu, i na osnivanje i rad projekta Knjiženstuo, teorija i istorija ženske književnosti na srpskom

1 Tekst je nastao u okviru projekta PATTERNS Lectures, koji realizuju WUS iz Austrije i Fondacija ERSTE i projekta Knjiženstvo - teorija i istorija ženske književnosti na srpskom jeziku do 1915. godine (br. 178029) Ministarstva prosvete, nauke i tehnološkog razvoja Republike Srbije. 
jeziku do 1915. godine u periodu od 2011. do 2016. godine. Kao projekat iz digitalne humanistike, Knjiženstuo pokazuje u kojoj meri digitalna humanistika pomaže marginalizovanom znanju i predstavlja način za prevazilaženje i prihvatanje razlika.

Ključne reči: ženska književnost na srpskom jeziku, ženske studije, istorija discipline, feministička teorija, Knjiženstvo

\section{UVOD}

Razvoj feminističkih, ženskih i kasnije - rodnih - studija u Srbiji započet je tokom socijalističkog perioda, u okviru Socijalističke Federativne Republike Jugoslavije - SFRJ. Prvi značajan datum u tom pogledu jeste skup Drug-ca žena, novi pristup ženskom pitanju, održan 1978. godine u Studentskom kulturnom centru u Beogradu. To je trenutak u kom su se "prepoznale" autorke i aktivistkinje koje su pojedinačno radile na sličnim problemima ili su imale sličan pristup, usmeren ka dekonstruisanju patrijarhalnih stereotipa. Tom prilikom su se nove ideje zapadnog feminizma oglasile u javnosti, dovodeći u pitanje dotadašnju državnu varijantu ravnopravnosti prema kojoj je žensko pitanje bilo rešeno zajedno sa klasnim pitanjem. Reakcije na pomenutu konferenciju kao na promociju "buržoaskog feminizma" pokazale su razlike u pristupima, ali su, za prve generacije postsocijalističkog feminizma, donekle i zamaglile prave doprinose socijalističkog perioda u kom je sačinjeno mnogo relevantnih studija iz sociologije i drugih disciplina. ${ }^{2}$ U svakom slučaju, zasluge socijalističkog perioda za uspostavljanje i održavanje društvene jednakosti i ženskih prava nikada nisu dovođene u pitanje. Naprotiv, otpor promenama koje su usledile tokom devedestih godina često se zasnivao upravo na svesti o tome da su ugrožena prava stečena u socijalizmu - pre svega reproduktivna prava i pravo na izbor, ali i drugi oblici jednakosti i socijalne zaštite.

\section{OTKRIVANJE RAZLIKA}

Trebalo je protekne četrnaest godina od pomenute konferencije da bi se u Srbiji formirale prve organizacije koje su se bavile feminističkom teorijom i feminističkim pristupom znanju. Ženske studije u Beo-

2 Spisak radova sa tog skupa, kao i pregled kasnije produkcije nalazi se u: Biljana Dojčinović-Nešić, Odabrana bibliografija radova iz feminističke teorïje/ženskih studija 1974-1996 (Ženske studije - posebno izdanje), Centar za ženske studije, Beograd, 1996. 
gradu započele su prvi kurs na simboličan datum - 8. marta 1992. godine. Za njihovo formiranje zaslužna je bila ženska grupa "Žene i društvo", osnovana tokom 80-ih, čije su aktivistkinje procenile da je došao trenutak da se, pored aktivizma, uvede i teorijski pristup. Tada je Srbija još uvek deo SFRJ, ali je jasno da zvanična politika vodi ka razaranju zemlje i ratovima - početkom jula 1991. počinje sukob u Sloveniji, a u proleće 1992. i rat u BiH. U Srbiji se u svakodnevnom životu oseća veliki pad standarda i potpuna nesigurnost u pogledu budućnosti. Sankcije UN uvedene su krajem maja 1992. godine, sve veći broj mladih ljudi napušta zemlju zbog ratne opasnosti, u želji da izbegnu prisilnu regrutaciju, kao i zbog ekonomskih problema.

U takvoj atmosferi formiraju se ženske studije, kao i niz ženskih aktivističkih grupa širom Srbije. Feministkinje unutar SFRJ, države za koju je tada bilo jasno da je osuđena na propast, delovale su po principima saradnje, komuniciranja i uvažavanja, sasvim suprotno onome što se događalo na makropolitičkom planu. Vezivala ih je svest o tome da rade na margini i činjenica da u okviru novog prestrojavanja društva, obeleženog nacionalističkom euforijom, većina zapravo postaje marginalizovana grupa. Podrška radu ženskih nevladinih organizacija koje predstavljaju otpor slomu građanskih vrednosti dolazila je od fondova poput "Otvorenog društva", "Hajnrih Bel”, "Kvina til kvina”, i drugih.

U tako visokopolitizovanom trenutku novi pristupi književnosti su, unutar feminističkog znanja, i te kako našli svoje mesto. Treba imati u vidu da su, kada je reč o književnim istraživanjima, prvi pojmovi sa zapada pristizali od druge polovine sedamdesetih godina. U časopisu Marksizam u svetu 1981. godine objavljen je temat o feminističkoj teoriji u okviru kog je preveden i uvod knjige Politike polnosti Kejt Milet; 1983. zagrebačka Republika objavljuje temat o ženskom pismu, a posle skupa Instituta za književnost i umetnost iz Beograda održanog u Dubrovniku 1986. godine, objavljen je temat o ženskom pismu u časopisu Književnost. ${ }^{3}$ Pravi procvat je interesovanje za feminističke poglede na književnost doživelo, međutim, tek od osnivanja ženskih studija 1992, i dvaju časopisa za književnost i feminističku teoriju 1995. godine. Na časovima iz književnosti u okviru ženskih studija ${ }^{4}$

3 Žensko pismo, temat u: Književnost, knj. LXXXIII sv. 8-9, str. 1386-1490.

4 Na ženskim studijama predavanja iz književnosti su nedostajala na prvom kursu, započetom osmog marta 1992. godine, ali su u narednih nekoliko godina doživele pravi "bum”. Od stupanja Centra pod okrilje Fakulteta političkih nauka, broj predavanja iz književnosti u drastičnom je opadanju. Statistika pokazuje sledeće - na prvom kursu (1992) učešće književnosti je o odsto; u školskoj 1992/3, književnost već čini 25 odsto kurseva; isto je 1997/8 u segmentu obaveznih, a 20 odsto u izbornim kursevima. Poslednji podaci koje posedujem odnose se na 2010/11, i tamo književnosti 
izučavana su pojedinačna književna dela, najčešće kroz prizmu pojma rod, kao i pojam ginokritike. Sam pojam rod (gender), koji označava društvenu konstrukciju polnosti krajem osamdesetih je uveden u područje društvenih nauka i humanistike u Srbiji, pre svega sociologije, a početkom devedesetih i u proučavanje književnosti. Ginokritika, kao istraživanje književnosti koju su pisale žene, predstavljala je reviziju tradicije upravo na bazi pojma rod, ${ }^{5} \mathrm{i}$ taj oblik feminističke kritike prekrio je talas interesovanja za žensko pismo iz osamdesetih godina.

Dva feministička časopisa ključna za feminističku kritiku i književnu produkciju počela su da izlaze 1995. godine: časopis za žensku književnost i kulturu ProFemina i časopis za feminističku teoriju, Ženske studije, koji je od 2000. preimenovan u Genero, i pod tim imenom izlazi i danas. U okviru ovih časopisa objavljena su tri temata o osnovnim pojmovima feminističke književne kritike i veliki broj pojedinačnih članaka na te teme. ${ }^{6}$ Jedna od rubrika u časopisu ProFemina, pod naslo-

\footnotetext{
i nema, jer su disciplinarne teme napuštene, a na kursu o ljubavi od 21 učesnika-ca, 3 (jedna sam ja) potencijalno se bave književnim temama. Tokom devedestih, od 40 opisanih knjiga u anotiranoj bibliografiji na kojoj sam radila tokom 1999. godine (na engleskom, neobjavljen materijal) svega četiri bi mogle da budu u našoj kategoriji feminističke kritike. Od toga, dve vrlo uslovno. Prva knjiga je monografija Nade Popović Perišić Književnost kao zavođenje (Prosveta 1989), a druga je moja knjiga Ginokritika: rod i proučavanje knjižvenosti koju su pisale žene (KD Sveti Sava 1993). Ostale dve su knjige Branke Arsić, na razmeđi filozofije i književnosti, a delom je isti slučaj i sa pomenutom knjigom Nade Popović Perišić. No, s druge strane, moramo imati u vidu i to da su same ženske studije bile deo interdisciplinarnih proučavanja književnosti, tako da bi statistički gledano, mogle da kažemo da je feministička kritika tokom 90-ih imala udeo od 10 odsto u ukupnoj produkciji knjiga.

5 V. o tome: http://www.zenskestudie.edu.rs/izdavastvo/elektronska-izdanja/casopis-zenske-studije/zenske-studije-br-5-6/237-ginokritika-istrazivanja-zenskeknjizevne-tradicije, link od 6. aprila 2016. godine.

60 tome sam, između ostalih, pisala i u sledećim tekstovima: "De-centered Pluralism of Methods: Feminist Literary Criticism in Serbia", u Gender and Identity: Theories from and/or Southeastern Europe, editors Jelisaveta Blagojević, Katerina Kolozova, Svetlana Slapšak, ATHENA; Research Center in Gender Studies Skopje and Belgrade Women's Studies and Gender Research Center, 2006, str. 281-296; "Decentrirani pluralizam metoda: feministička književna kritika u Srbiji”, ProFemina, god. 10, br. 37/40, 2004/2005, str. 110-121; “Žensko pismo, problem roda i ginokritika", u Teorijsko-istorijski pregled komparatističke terminologije kod Srba, ogledna sveska br. 1, ur. B. Stojanović-Pantović, Beograd: KD Sveti Sava, 2006, str. 149-166; "Pojam roda i istorija književnosti", u Teorijsko-istorijski pregled komparatističke terminologije kod Srba, ogledna sveska br. 2, ur. B. Stojanović-Pantović, Beograd: KD Sveti Sava, 2007, str. 165-180; "Teaching feminist literary theory: a postcard from Serbia”, Filolog, časopis za jezik, književnost i kulturu, Univerzitet u Banjoj Luci, Filoloski fakultet, II/2010, str. 115-121. V. i Igor Perišić, Kritika i metakritika, IKUM, Beograd, 2015. Prva regionalna istorija jeste knjiga Lade Čale Feldman i Ane Tomljenović Uvod u feminističku kritiku. V. Lada Čale-Feldman, Ana Tomljenović, Uvod u feminističku književnu kritiku, Zagreb: Leykam International, 2012.
} 
vom "Portret prethodnice", presudno je uticala na obraćanje sopstvenoj ženskoj književnoj produkciji, za razliku od prvobitnog insistiranja na prevodima stranih tekstova, što je tipično za razvoj nove oblasti.

Hronološki, dakle, razvoj feminističkog znanja u Srbiji povezan je sa nastupanjem postsocijalističkog perioda. To svakako nije slučajno jer je feministička teorija deo postmoderne priče u kojoj se insistira na razlici i uvažavanju razlika umesto na jedinstvu pa i uniformnosti. Što se uloge književnosti u feminističkoj teoriji tiče, ne treba se mnogo čuditi istaknutom mestu koje je zauzimala barem u tim "pionirskim" danima. Prednost književnosti je u tome što ona u sebe apsorbuje elemente stvarnosti i predstavlja diskurs koji je privilegovan utoliko što može da se slobodno poigrava tim činiocima. Dakle, pre strogih logičkih analiza dolazi umetnost koja često otkriva više nego bilo kakva studija, računajući i na emociju i na intuiciju. U feminizmu s kraja šezdesetih godina u SAD književnost je često imala ulogu terapije, da bi se potom vraćala u učionice ali uvek sa tim aspektom emocionalnog, ličnog i privatnog (koje jeste "javno"). U Srbiji, feministička kritika je imala politički aspekt prepoznavanja razlika, a sama tvrdnja da je književnost uvek politična predstavljala je veliki preokret, naročito u akademskim književnim tumačenjima.

\section{"RAZLIKA U AKADEMIJI"}

Kada je o akademskim tumačenjima književnosti reč, svakako da pojam razlike nije bio sasvim nov na početku devedesetih godina. Dekonstrukcija i poststrukturalizam uopšte bili su uveliko poznati, ali je feministička kritika po prvi put jasno otelovila taj pojam - kao žensko u tekstu, ali i kao ženu - autorku koja dela u određenim istorijskim i društvenim okolnostima i čija je psihološka dinamika drugačija nego u slučaju pisaca. Takav pristup je predstavljao veliku promenu pre svega za same predavačice, proizišle iz škola imanentne analize, ${ }^{7}$ ali isto tako i za publiku. No, feministička kritika je prilično dugo čekala na to da stupi u akademski prostor i za to vreme je predavana isključivo na ženskim studijama u okviru nevladinih organizacija. ${ }^{8}$ Jasno

7 V. o tome Biljana Dojčinović-Nešić, "Kako predavati feminističku kritiku: lično iskustvo”, Kreativno vaspitanje, Beograd, broj 4, 1. mart 1999, str. 25-30; “Teaching feminist literary theory: a postcard from Serbia”, Filolog, časopis za jezik, književnost i kulturu, Univerzitet u Banjoj Luci, Filološki fakultet, II/2010, str. 115-121.

8 Godine 2003. osnovan je ACIMSI Centar za rodne studije (CRS) Univerziteta u Novom Sadu (odlukom Senata kojim je predsedavala rektorka Fuada Stanković, a predlog plana i programa obrazlagala profesorka Svenka Savić). Najpre su to bile specijalističke i magistarske, sledeće godine doktorske, da bi tokom bolonjskih 
je da je diskurs razlike bio previše uznemirujući tokom devedesetih da bi bio uvažen od strane zvaničnog obrazovnog sistema, a osim toga, kad god se nacija predstavlja kao ugrožena sve ostalo završava na margini - žene i žensko pitanje među prvima.

Prvu istoriju ženske književnosti na srpskohrvatskom jeziku objavila je 200o. godine Silija Hoksvort (Celia Hawkesworth), prevoditeljka i profesorka srpskih i hrvatskih studija na Univerzitetu u Londonu. Knjiga Voices in the Shadows (Glasovi u senci) izašla u izdavačkoj kući Centralnoevropskog univerziteta u Budimpešti, bila je ujedno i prva gender knjiga ovog izdavača. Ova studija predstavlja istorijski niz ženske književnosti u Srbiji i Bosni i Hercegovini i, mada napisana za strane čitaoce, na engleskom, odavno je važan izvor informacija i za zainteresovane iz srpske kulture. Njen status neprevedene knjige sve do ovog trenutka mogao je da označava i status ženske književnosti u srpskoj kulturi - druga, na drugom, drugačijem jeziku.

Takav slučaj nije bio moguć sa knjigom Magdalene Koh (Magdalena Koch) koja je 2007. objavljena na poljskom ... kiedy dojrzejemy jako kultura...Twórczość pisarek serbskich na początku XX wieku (kanon-genre-gender). Da bi se upisala u ovdašnju književnu teoriju i istoriografiju, morala je biti prevedena, što se dogodilo pet godina posle poljskog izdanja, 2012. U trenutku kada je napisana izgledalo je kao da je istorija srpske ženske književnosti moguća samo na stranom jeziku. Prevod menja tu situaciju - istorija srpske ženske književnosti "vraćena" je time u svoj izvorni, maternji jezik, iznova je osvetljena, skupa sa teorijom koja time biva saobražena potrebama ove kulture, prevedena, preneta i ponašena. Studija ... kada sazremo kao kultura... Stvaralaštvo srpskih spisateljica na početku XX veka (kanon-žanr-rod) započinje istorijskim pregledom ženskog književnog stvaralaštva na srpskom, ali se najdetaljnije bavi početkom dvadesetog veka kao vremenom intenzivnije aktivnosti srpskih spisateljica. Knjiga je dobila naslov na osnovu dela rečenice Isidore Sekulić kojom se predviđa da će stvaralaštvo srpskih spisateljki (konkretno je reč o Milici Janković) biti pravedno ocenjeno onda kada se "smirimo, kada sazremo kao kultura". Magdalena Koh je pozicionirala ženske glasove unutar šireg kulturnog konteksta, a samu različitost ženske književnosti pokazala je pre svega na pri-

procesa postali akreditovani master (2011) i doktorski program (2012). Rodne studije, započete kao specijalistički program, a potom kao magistarske studije, te deo doktorskog programa, nastale su na Fakultetu političkih nauka u Beogradu, takoreći izrasle iz nevladinog Centra za ženske studije. O ulozi književnosti u tim programima nemam podatke. 
meru četiri modernističke spisateljice - Jelene Dimitrijević, Isidore Sekulić, Milice Janković i Danice Marković. Zašto baš njih četiri? Zato što su one primećene u savremenoj recepciji, na samom početku 20. veka, a potom su, sa izuzetkom Isidore Sekulić, praktično izbrisane sa mape srpske književnosti, da bi tek devedesetih, na talasu feminističke teorije, počelo da se ponovo govori o njima.

\section{PRIHVATANJE RAZLIKA}

U drugoj deceniji 21. veka sam pojam tradicije dobija potpuno drugačiji oblik nego što je to bilo pre dvadeset i više godina. O ženskoj književnoj tradiciji više se ne razmišlja kao o neprekinutom nizu u kom valja popuniti lakune, već kao o strukturi nalik na mrežu koja nikada ne može biti potpuno završena. Za takav pristup možemo da zahvalimo novim informacionim tehnologijama koje su dobile sopstvenu primenu u humanistici i naišle na naročito povoljno tle u oblasti ženskih studija.

Prvi pokušaj da se internet iskoristi kao medij za podsticanje upoznavanja sa srpskom ženskom književnošću jeste istraživački projekat nazvan Zavera nečitanja: mesto, sudbina i značaj ženskog književnog stvaralaštva u srpskoj kulturnoj baštini (2001-2004). Projekat je proizišao iz predavačkog programa Centra, uz cilj da reafirmiše žensku književnost sa istorijskog aspekta, da stvori teorijski okvir za ponovno čitanje i razumevanje ženskog pisma, kao i da ustanovi tradiciju ženskog spisateljstva u Srbiji. Naziv projekta predložila je Vladislava Gordić-Petković, jedna od učesnica projekta, pored Tatjane Rosić, Dubravke Đurić i Biljane Dojčinović. Ideja je bila da se na srpskom i engleskom predstave tekstovi o ženi i književnosti, sa aspekta istorije i feminističke teorije književnosti. Tekstovi pomenutih autorki, kao i Svetlane Slapšak, Snežane Samardžije i Ljiljane Pešikan-Ljuštanović nalaze se na sajtu Centra za ženske studije. ${ }^{9}$

Po uzoru na evropsku bazu podataka Women Writers (http:// neww.huygens.knaw.nl/), nastalu iz pokušaja da se popiše i opiše recepcija Žorž Sand u Evropi, ${ }^{10}$ formirana je i baza podataka Knjiženstuo u okviru projekta Knjiženstuo, teorïa i istorija ženske književnosti na srpskom jeziku do 1915. koji finansira Ministarstvo prosvete, nauke i tehnološkog razvoja Republike Srbije u periodu od 2011. do 2015. godine. Cilj projekta je da rekonstruiše istoriju ženske književnosti

9 http://www.zenskestudie.edu.rs/izdavastvo/elektronska-izdanja/istrazivanja/ zavera-necitanja, link od 4. februara 2015.

10 B. Dojčinović, M. Koch, http://www.knjizenstvo.rs/magazine.php?text=25. 
na srpskom jeziku kao i da teoretizuje njene specifičnosti, preoblikujući postojeće, uglavnom zapadne, pojmove i modele. Sam termin knjiženstvo zvuči kao kombinacija reči knjiga i ženstvo, odnosno, kao kovanica koja bi trebalo da označi žensku književnost. Međutim, knjiženstvo nije neologizam, već termin ${ }^{11}$ blizak reči knjižestvo koja je bila dublet za književnost.

U savremenoj upotrebi, ovaj pojam odgovara svemu onome što ženska književnost teži da obuhvati - takozvanu lepu književnost, ali i privatne oblike izražavanja kao i ono što bismo danas nazvali publicistikom. Patinirani prizvuk reči knjiženstvo upućuje na ideju književne istorije, a njena obuhvatnost u pogledu onoga šta književnost ovde znači, srećno je združena sa terminom ženstvo koji kao da podrazumeva ali i prevazilazi pojmove ženstvenosti, ženskosti i feminizma.

Dva osnovna elementa projekta jesu digitalna baza podataka i časopis. Knjiženstvo, časopis za studije književnosti, roda i kulture profilisan je kao međunarodni elektronski časopis koji se od drugog broja nalazi i u bazi podataka EBSCO. Povezan je sa bazom podataka Knjiženstvo sa kojom deli istu početnu adresu, www.knjizenstvo.rs, ali i sa drugim elektronskim izvorima preko linkova u tekstovima.

Digitalna baza podataka Knjiženstvo, teorija i istorija ženske književnosti na srpskom jeziku do 1915. godine sadrži podatke o stvaralaštvu srpskih književnica od srednjeg veka do 1915. godine. Reč je o osnovnim biografskim i bibliografskim podacima, podacima o prevodima, ženskim časopisima, vezama sa drugim književnicama, srpskim i stranim, međusobnim uticajima i, u nekim slučajevima, linkovima koji vode ka digitalizovanim tekstovima.

Baza podataka se nalazi na adresi http://knjizenstvo.etf.bg.ac.rs/ sr. Najjednostavnije je do nje doći preko adrese sajta, to jest, početne stranice, www.knjizenstvo.rs. Kada se pritisne neko od polja AUTORKE, RADOVI, SERIJSKE PUBLIKACIJE, RECEPCIJA otvaraju se sledeći skupovi podataka:

1) Biografski podaci o autorkama: važni datumi, podaci o privatnom i profesionalnom životu autorke, bibliografski podaci, linkovi ka drugim sajtovima, itd.

2) Informacije o radovima: datumi objavljivanja, izdanja i ponovljenih izdanja, linkovi ka drugim sajtovima i digitalizovanim radovima, itd.

3) Podaci o serijskim publikacijama: uredništvo, dinamika izlaženja, saradnici, orijentacija časopisa i sl.

4) Podaci o recepciji, poput kritika u periodici, prevodi.

11 V. "knjiženstvo" u Rečniku srpskohrvatskog književnog i narodnog jezika, knjiga IX. 
Baza takođe ima i stranice na engleskom jeziku za svaku autorku, kao i vezu sa bazom podataka Women Writers (http://neww.huygens. knaw.nl/).

Radovi, recepcija i drugi linkovi međusobno su povezani. Na primer, povezane su serijske publikacije i radovi autorki zastupljenih u bazi, kao i autorke sa recepcijom ženske književnosti. Ovakva vrsta rada zahteva da se o književnim aspektima razmišlja na način koji uključuje preglednost, jednostavnost i dostupnost, kao i mogućnost lakog korišćenja podataka.

Do sada imamo više od 150 imena u bazi i pet brojeva časopisa, dve međunarodne konferencije $\mathrm{e}^{12}$ i sve veći broj saradnica i saradnika. U oktobru 2015. objavljen je i zbornik "u papiru”. Reč je o zbirci tekstova o našim književnicama koje su postale aktivne do 1915. godine. Među njima su, pored Jefimije, Eustahije Arsić, Milice Stojadinović Srpkinje i modernistkinje od Danice Marković, Jelene Dimitrijević do Anice Savić Rebac. ${ }^{13}$ Tu su i tekstovi o ženskim časopisima koji su bili oznaka modernizma. Tim zbornikom praktično je zaključena jedna, rekla bih, druga faza, feminističke kritike u Srbiji. Prva se odnosila na intenzivno učenje i prevođenje, doslovno i prenosno, teorije koja je dolazila sa zapada. Druga faza predstavlja proizvodnju sopstvenog znanja, znanja o sebi, što je istovremeno i konstruisanje sopstvenog identiteta. Ta faza je tek započeta, a sam zbornik označava onaj trenutak u kom kolektivni napor stvara nešto što je iz perspektive tradicionalne istorije književnosti vidljivo - solidno zdanje u obliku knjige. No, u eri digitalne humanistike s bazom podataka Knjiženstvo započet je mnogo uzbudljiviji razvoj koji će, pored doprinosa najistaknutijih spisateljki koje su delovale do sredine 20. veka na srpskom jeziku, na svetlo dana izneti i mnoga sada zaboravljena, marginalizovana imena. Digitalna humanistika ${ }^{14}$ se tako ispostavlja kao pristup idealan za prihvatanje razlika koje je feministička književna kritika

$12 \mathrm{O}$ tome na http://www.knjizenstvo.rs/magazine.php?text=30 link od 6. aprila 2016. godine. http://www.knjizenstvo.rs/magazine.php?text=140 link od 6 . aprila 2016. godine.

13 Zbornik se nalazi na adresi: http://www.knjizenstvo.rs/news_view.php?id=22.

$14 \mathrm{O}$ odnosu feminističke kritike i digitalne humanistike v. moj tekst "Istorija discipline koja to nije: od pojma roda do digitalne humanistike", u Komparativna književnost: teorija, tumačenja, perspektive, priredile Adrijana Marčetić, Zorica Bečanović Nikolić, Vesna Elez = Encompassing Comparative Literature: theory, interpretation, perspectives, edited by Adrijana Marčetić, Zorica Bečanović Nikolić, Vesna Elez, Beograd, 2016, str. 75-84. Elektronska verzija na: http://www. fil.bg.ac.rs/wp-content/uploads/ZBORNIK-Komparativna-knjizevnost-Teorijatumacenja-perspektive.pdf link od 6. aprila 2016. 
osvestila - ne samo među piscima i spisateljkama, već i među samim spisateljkama, ali ponajpre među centrom i (polu)periferijom, ${ }^{15}$ omogućavajući stvaranje, prezentovanje i korišćenje znanja koje je donedavno bilo potcenjeno, zaboravljeno i osuđeno na to da nestane.

Tekst je prvobitno objavljen na nemačkom jeziku: Biljana Dojčinović, "Die Akzeptanz Der Differenz. Feministische Kritik in Serbien in postsozialistischen Zeit”, u Angela Richter, Tijana Matijević, Ewa Kowollik (Hg.), Schwimmen gegen den Strom? Diskurse weiblichen Autorschaft im Postjugoslawischen Kontext, Slavica Varia Halenska, 13, 2018, Lit. Verlag Dr. W. Hopf, Berlin, str. 99-114.

\section{LITERATURA}

Blagojević, Marina. (2009). Knowledge Production at the Semiperiphery: A Gender Perspective. Beograd.

Dojčinović (Dojčinović-Nešić), Biljana.

(1997). Odabrana bibliografija radova iz feminističke teorïje/ženskih studija 1974-1996 (Ženske studije - posebno izdanje), Beograd.

(1999). "Kako predavati feminističku kritiku: lično iskustvo", Kreativno vaspitanje, Beograd, broj 4, 1. mart 1999, str. 25-30.

(2006). "De-centered Pluralism of Methods: Feminist Literary Criticism in Serbia”, u Gender and Identity: Theories from and/or Southeastern Europe, editors Jelisaveta Blagojević, Katerina Kolozova, Svetlana Slapšak, ATHENA; Research Center in Gender Studies Skopje and Belgrade Women's Studies and Gender Research Center, 281-296.

(2006). "Žensko pismo, problem roda i ginokritika", Teorijsko-istorijski pregled komparatističke terminologïje kod Srba, ogledna sveska br. 1, ur. B. Stojanović-Pantović, Beograd, str. 149-166.

(2007). "Pojam roda i istorija književnosti", u Teorijsko-istorijski pregled komparatističke terminologije kod Srba, ogledna sveska br. 2, ur. B. Stojanović-Pantović, Beograd, str. 165-180.

(2010). "Teaching feminist literary theory: a postcard from Serbia", Filolog, Časopis za jezik, književnost i kulturu, Univerzitet u Banjoj Luci, Filoloski fakultet, II/2010, str. 115-121.

(2013). "Nevolje sa ženskim, nevolje s književnošću: pojmovi žensko pismo i ginokritika na poluperiferiji”, u Pojmounik uporedne kn-

15 Vidi Blagojević 2009. 
jiževnosti: zbornik radova, urednici Bojan Jović, Tihomir Brajović, Institut za književnost i umetnost, Beograd, str. 345-375.

(2016). "Istorija discipline koja to nije: od pojma roda do digitalne humanistike", u KOMPARATIVNA knjižeunost: teorija, tumačenja, perspektive/priredile Adrijana Marčetić, Zorica Bečanović Nikolić, Vesna Elez = Encompassing Comparative Literature: theory, interpretation, perspectives, edited by Adrijana Marčetić, Zorica Bečanović Nikolić, Vesna Elez, Beograd.

(2011). Dojčinović, Biljana, Koch, Magdalena. "In Search of Women Authors", an interview with Suzan van Dijk, http://www.knjizenstvo.rs/magazine.php?text $=25$.

\section{ELEKTRONSKI IZVORI}

Knjiženstvo, teorija i istorija ženske književnosti na srpskom jeziku do 1915. godine, www.knjizenstvo.rs.

\section{ACCEPTING DIFFERENCE: FEMINIST CRITICISM IN SERBIA IN THE POST-SOCIALIST PERIOD}

The aim of this text is to represent the history of an interdisciplinary research field - the field of difference in relation to the actual literary criticism, and to feminist theory. The text starts with the information that, in socialist Yugoslavia, western feminist ideas resonated for the first time at the end of the " 70 s, at the conference Drug-ca žena; however, tumultuous feminist-theoretical activity had its true beginnings in the nineties. The foundation of the Women's Studies Centre, lectures from the literary studies at the Centre, and articles and books published at that period bear witness to the strong development of feminist criticism outside of the academic setting. The second part of the text refers to the entry of gender and theory of difference into the academic sphere, and the foundation and work of the project Knjiženstvo, Theory and History of Women's Writing in Serbian until 1915 from 2011 to 2016. As a digital humanities project, Knjiženstvo shows to what extent digital humanities help marginalised knowledge and represent a way of overcoming and accepting difference.

Keywords: women's literature in Serbian language, women's studies, history of a discipline, feminist theory, Knjiženstvo 